\title{
DEFINING CLINICAL PUBLIC HEALTH - PUBLISHED 44(2) JUNE 2021
}

\section{Editor's Note}

In this issue, Bernard Choi and colleagues have presented their vision of clinical public health as an approach to address complex health issues in our health system. To help stimulate discussion, CIM invited commentaries from two distinguished scientists to present their views on the concept. We hope this discussion will ultimately guide the direction public health will follow.

Robert Bortolussi, MD, FRCPC, FCAHS

\section{CAN PUBLIC HEALTH BE "CLINICAL"?}

Whenever a new academic/professional discipline or sub-discipline of public health $(\mathrm{PH})$ is proposed, several questions should be asked. First, in what ways is the new entity of clinical public health ( $\mathrm{CPH}$ ) different from the existing entity of $\mathrm{PH}$ ? Qualities attributed to $\mathrm{CPH}$, such as multidisciplinarity, collaboration, promotion of interprofessional education, are not specific to $\mathrm{CPH}$ but already encompassed by $\mathrm{PH}$. Second, is there a separate and distinct body of knowledge, set of theories and scope of practice of CPH that justifies its creation? The answer is clearly no, as the knowledge base of $\mathrm{CPH}$ is exactly the same as that of $\mathrm{PH}$. Third, does its creation advance or hinder the development of $\mathrm{PH}$ ? An unintended and undesirable consequence may be the creation of a division within $\mathrm{PH}$, from the exclusion of those who are not also practising clinicians.

Finally, the label of "clinical" is problematic. Proponents of $\mathrm{CPH}$ are entitled to ascribe any meaning to the term: as Humpty Dumpty said to Alice, "when I use a word, it means just what I choose it to mean". However, the Oxford English Dictionary defines "clinical" as "designating and pertaining to the bedside of a sick person". One could argue that "clinical public health" is an oxymoron, since public health is primarily devoted to promoting health and preventing disease in the population, rather than engaged in one-to-one interactions with patients.

As Choi et al. found out from their survey, there was no consensus on what $\mathrm{CPH}$ should be. I add my voice to the "nays".

Kue Young, MD, PhD, FRCPC, FCAHS

Professor Emeritus and Former Dean, School of Public Health, University of Alberta, Edmonton, AB, Canada

Professor Emeritus, Dalla Lana School of Public Health, University of

Toronto, Toronto, ON, Canada

\section{ON 'DEFINING CLINICAL PUBLIC HEALTH'}

If the current coronavirus disease 2019 epidemic has taught us anything, it is that creating successful public health policy is an extremely difficult task, requiring a highly multidisciplinary approach. What this reader finds so striking about the article entitled "Defining clinical public health" is that it points to a longstanding and widespread sense amongst a variety of public health researchers that their particular specialty is somehow not already included in the discipline known as "public health". That a term coined in the 1970 s could be officially adopted over the last decade by the University of Toronto, by the George Washington University and by the University of South Carolina, and yet still engender disagreement as to what it means speaks volumes about the siloed structure of academic public health in North America. It would be truly great if we could come out of this with a sense that the discipline of "public health" has room for everyone with something to contribute, and this month's article on defining clinical public health might be a step in that direction. Hopefully, one consequence of this terrible pandemic will be a renewed understanding that we're all in this together, not just socially but also academically.

\section{Tim Ramsay, PhD}

Scientific Director, Ottawa Methods Centre (OMC), Ottawa Hospital Research Institute, ON, Canada 